\title{
EDUCAÇÃO EM SAÚDE NO ÂMBITO ESCOLAR: AÇÕES DA TERAPIA OCUPACIONAL
}

\author{
Pâmela dos Santos Rocha ${ }^{1 *}$ \\ Shirlley de Souza Silva ${ }^{2}$ \\ Janielly Bezerra Raimundo ${ }^{3 *}$
}

\section{INTRODUÇÃO}

O conceito e a posterior prática da educação em saúde surgiu nos últimos vinte e cinco anos em países como o Canada, E.U.A e países da Europa Ocidental, nesse período, quatro conferências internacionais sobre promoção da saúde foram as mais importantes para essa construção. Realizaram-se em Ottawa em 1986, Adelaide em 1988, Sundsval em 1991 e Jakarta em 1997, estas estabeleceram as bases conceituais e políticas da promoção em saúde. E em 1992 na América Latina realizou-se a Conferencia Internacional de Promoção a Saúde, onde trouxe formalmente o tema para o contexto regional (BUSS, 1999).

A educação em saúde é uma prática social, devendo ser centrada na problematização do cotidiano, na valorização da experiência de indivíduos e grupos sociais e na leitura das diferentes realidades. Vista como prática social, a educação em saúde passou a ser repensada como processo capaz de desenvolver a reflexão e a consciência crítica das pessoas sobre as causas de seus problemas de saúde.

Neste sentido, as ações educativas podem proporcionar sensibilização acerca de problemas de saúde, evitando doenças ou agravamento de alguma forma pré- instalada. Assim, é importante destacar que estas ações preventivas são bastante benéficas, principalmente do ponto de vista econômico e assistencial, pois

\footnotetext{
${ }^{1}$ Graduação em Terapia Ocupacional - Universidade Estadual de Ciências de Saúde de Alagoas UNCISAL, E-mail: to.pamelarocha@gmail.com

${ }^{2}$ Graduação em Terapia Ocupacional - Universidade Estadual de Ciências de Saúde de Alagoas UNCISAL, E-mail: toshirlley@gmail.com

${ }^{3}$ Graduação em Terapia Ocupacional - Universidade Estadual de Ciências de Saúde de Alagoas UNCISAL, E-mail: janiellybezerra@gmail.com
} 
sendo conduzidas de maneira correta podem diminuir a incidência de doenças e contribuir para a diminuição do número de indivíduos que buscam os serviços de saúde de maior complexidade (COSTA, SILVA e DINIZ, 2008).

Como afirma Pereira (2003), um fator importante a se destacar é que a educação e a saúde estão interligadas, visto que, são espaços de produção e aplicação de saberes destinados ao desenvolvimento humano, onde se pode notar interseção e modo de operá-las que muitas vezes é feito inconscientemente. Dessa forma, compreende-se que o profissional de saúde pratica educação em saúde em seu cotidiano profissional sem que se perceba como tal.

Dessa forma, a escola se configura como um dos alicerces da educação, da cidadania e da formação de uma nação, pois é através dela que a criança inicia sua educação, sua integração e inclusão social, seus relacionamentos e seus potenciais, ou seja, relações complexas que se estendem e irão de certa forma influenciar aspectos relacionados ao seu desenvolvimento durante toda a vida (LIBERAL 2005).

Assim, escola é um espaço de extrema importância para o desenvolvimento de conhecimentos e habilidades, sendo relevante um conjunto de profissionais de diferentes saberes para essa construção, levando em conta que os aprendizes estão em período importante de suas vidas, a infância e adolescência, sendo estas, etapas críticas de crescimento e desenvolvimento (GUBERT, SANTOS, ARAGÃO, et al. 2009).

Neste sentido, um profissional da saúde que se enquadra nessa configuração de desenvolvimento entre educação e saúde é o Terapeuta Ocupacional, este, trabalha como agente promotor da educação em saúde, pois dentre suas competências, ele busca compreender as relações saúde-sociedade como também as relações de exclusão-inclusão social, bem como participar da formulação e implementação das políticas sociais sejam elas setoriais (políticas de saúde, infância, adolescência, educação, trabalho, etc.) ou intersetoriais.

Logo, a Educação é um dos campos de intervenção da Terapia Ocupacional, caracterizado fundamentalmente pela interdisciplinaridade, e o seu objeto é o sujeito coletivo, ou seja, os educadores, os estudantes, os equipamentos escolares e os familiares, tendo como finalidade o alcance dos diferentes sujeitos, bem como a organização de ações de saúde apropriadas, que considerem o 
fortalecimento da potência de todos os envolvidos no âmbito escolar (ROCHA, 2007).

Sendo assim, no ambiente escolar, o indivíduo em determinadas etapas da vida aprende atitudes e habilidades que são articuladas às suas experiências vivenciadas no cotidiano. As conquistas orientam o aluno a reconhecer e expressar suas necessidades, possibilitando a oportunidade de refletir sobre seu papel histórico, colaborando para possíveis transformações por meio da consciência e mudança social.

Diante do exposto, o objetivo desse trabalho foi favorecer temas de saúde por meio de profissionais da saúde dentro do ambiente escolar, utilizando um espaço rico para transmissão de informações de saúde que são relevantes para os indivíduos participantes da ação, considerando suas realidades e necessidades para potencializar as demandas escolares e favorecer ações que contemplassem educação e saúde.

\section{METODOLOGIA}

Trata-se de um relato de experiência realizado por meio do Estágio Obrigatório do Curso de Terapia Ocupacional da Universidade Estadual de Ciências da Saúde de Alagoas - UNCISAL, a disciplina vinculada foi a de Terapia Ocupacional na Saúde Coletiva. A intervenção foi realizada na Escola Estadual Silvestre Péricles, localizada no bairro do Pontal da Barra na cidade de Maceió/AL, o público alvo da ação foi adolescentes com a idade de 12 a 14 anos.

A atuação das estagiárias se deu a partir da relação entre os setores de educação e de saúde, na perspectiva de proporcionar melhor qualidade de vida, com objetivo de desenvolver um conjunto de ações atendendo aos adolescentes numa visão biopsicossocial, visando estratégias com o domínio dos determinantes sociais em saúde. Dado o contexto de vida dos adolescentes através de educação em saúde e promoção da saúde, dessa forma, entende-se que a parceria entre a saúde e a educação constitui um grande potencial na construção de sujeitosadolescentes. É importante destacar que alguns dos alunos que participaram da 
ação faziam parte de outra iniciativa social chamada Bombeiro Mirim, realizada pelo corpo de bombeiros situado próximo ao bairro onde residem.

A faixa etária de idade escolhida resultou da disponibilidade de horário das estagiárias, que na ocasião dispunha apenas do horário da tarde para realizar as ações. Foi organizado um cronograma com oito encontros, divididos de acordo com as séries dos alunos, e cada grupo teve um tema específico de acordo com sua faixa etária de idade.

A observação e escuta dos adolescentes foi feita a partir de rodas de conversas a fim de obter uma visão geral do interesse do grupo e o que sabiam sobre o tema sugerido no início da conversa.

Durante as ações foram utilizados recursos de baixo custo a fim de promover um maior aprendizado, pois as dinâmicas e brincadeiras representam técnicas afetivo-participativas na educação em saúde.

A técnica de usar brincadeiras ou jogos para trabalhar determinado tema já é usada há um tempo, como é o exemplo de Lefévre (1980), que com seus cartazes trabalhou o tema da esquistossomose, onde afirmou que apenas conteúdos que refletem de perto a cultura dos educandos têm a possibilidade de provocar mudanças nos mesmos.

O tema em comum com todas as faixas etárias foi à higiene, a demanda dos temas surgiu de alguns professores, pois os mesmos relatavam que não conseguiam aborda-los em sala de aula.

Os temas subsequentes foram:

- Puberdade: Significado, quais as mudanças advindas dessa nova etapa na vida do adolescente, do ponto de vista biológico e comportamental.

- Higiene: Sugestão de como deveria ser realizada.

- Corpo mal cheiroso: Explicação biológica do que acontecia com o corpo para gerar o suor, e consequentemente o odor assim como é algo normal, a produção do suor varia de acordo com o indivíduo. E como o forte odor pode ser evitado.

- Chulé: Discussão sobre o que causa o odor, a umidade que gera o chulé também pode gerar outros tipos de problemas como a micose, no caso de micose não é aconselhável utilizar talco ou outros, pois resolve apenas com fungicida, e formas de evitá-lo. 
- Mau hálito: Conversa acerca das causas, formas de prevenção e como tratar.

- Esmegma: O que é, onde se localiza, o que pode causar e prevenção.

- Violência: O que sabiam sobre o tema, discussão sobre já terem presenciado ou sofrido algum tipo de violência.

- Rede social: Abordou-se o uso, o que costumavam acessar e postar na internet e os cuidados devidos ao utilizar esse recurso.

É importante ressaltar que em todos os encontros os temas foram abordados de forma lúdica, utilizando sempre linguagem acessível aos adolescentes para melhor compreensão, além disso, é extremamente importante visualizar os alunos como agente disseminador do conhecimento no âmbito familiar e na comunidade onde está inserido.

\section{RESULTADOS E DISCUSSÃO}

As hipóteses que nortearam a proposta deste trabalho foram de que os problemas de saúde devem ser prevenidos pelo esforço individual e pela adesão a hábitos corretos de vida; os problemas de saúde da população podem ser decorrentes da falta de informação; a educação deve ser concebida como a transmissão de conteúdos neutros e descontextualizada. Assim, a educação em saúde justifica-se na perspectiva de responsabilizar os indivíduos por sua saúde. Neste foco, a intervenção da Terapia Ocupacional contribui como articulador social, onde demanda a constituição de um campo de conhecimento teórico e prático que implica na possibilidade de compreender, articular e produzir reflexões com a demanda abordada, além de considerar a escola, assim como outras instituições que promovem processos sócio-educativos, como equipamentos sociais relevantes que permitem o acesso de grupos populares à visibilidade social, às experiências educacionais, culturais e/ou, ainda, possibilitem melhores condições de vida. Dessa forma, como afirmam Demarzo e Aquilante (2008), a escola tem como missão primordial desenvolver processos de ensino-aprendizagem e desempenhar um papel fundamental na formação e atuação das pessoas em todos os âmbitos da vida social. Juntamente com outros espaços sociais, ela cumpre papel decisivo na formação dos estudantes, na percepção e construção da cidadania e no acesso às 
políticas públicas. Logo, pode tornar-se espaço para ações de promoção da saúde para crianças, adolescentes e jovens adultos.

A inserção interdisciplinar idealiza uma visão de sociedade e de mundo e de relação solidária entre as pessoas, porém parte do desafio de como construir um campo comum de práticas e saberes centrados na participação da população, sendo importante o vínculo com este público para assim surgirem ações mais efetivas dentro da dinâmica da comunidade, levando em consideração seus saberes. Sabendo que a educação em saúde é o conjunto de ações potencializadoras que contribuem para ampliação do grau de autonomia dos indivíduos, é importante intervir tendo como base a valorização da singularidade do sujeito, bem como do coletivo, por meio da transmissão de informações e do apoderamento de políticas públicas, instituições e organizações dentro do território. Nesse contexto, encontrase o Programa Saúde na Escola (PSE), uma política intersetorial entre educação e saúde que compreende a escola como espaço privilegiado de práticas de promoção de saúde e prevenção de agravos e doenças, por meio de ações compartilhadas que têm como corresponsáveis atores de ambos os setores com o objetivo de contribuir para a formação integral dos estudantes, com vistas ao enfrentamento das vulnerabilidades que comprometem o pleno desenvolvimento de crianças e jovens da rede pública de ensino. O respectivo projeto visou estimular ações de educação em saúde no âmbito escolar, buscando implementar planos de ações dinâmicos e contínuos, que se incluíam metas, processos e estratégias, direcionadas aos alunos de nível fundamental ( $7^{\circ}, 8^{\circ}$ e $9^{\circ}$ ano), buscando tratar os temas abordados de forma lúdica e de fácil compreensão tais indivíduos.

A estratégia de utilizar perguntas simples e que contemplassem as dúvidas dos adolescentes teve o propósito de despertar a reflexão crítica e problematizadora dos jovens permitindo que seus saberes individuais fossem compartilhados com os colegas. Isso surtiu um efeito positivo, pois os adolescentes sentiram-se importantes uma vez que, seus saberes estavam sendo ouvidos e agregados às novas informações fornecidas pelas estagiárias.

Nestas atividades educativas, pode-se avaliar, através de questionamentos, que os adolescentes haviam assimilado de forma satisfatória os conteúdos teóricos discutidos. Em todas as nossas atividades, foi possível obter êxito, pelo fato de que, em todos os retornos à escola, percebeu-se que a nossa 
mensagem foi captada pelos alunos, uma vez que, sempre que perguntávamos algo sobre um tema já abordado anteriormente, as respostas corretas eram imediatas.

Assim, esta experiência mostrou-se uma importante ferramenta para motivar a comunidade escolar em questões relacionadas à promoção da saúde em busca da autonomia, da valorização do autocuidado e do desenvolvimento de habilidades, reconhecendo que as atividades são baseadas em uma descoberta espontânea e em uma aprendizagem significativa dos envolvidos.

\section{CONCLUSÃO}

A educação em saúde é uma das principais estratégias para promover a responsabilidade social incentivando o indivíduo a desenvolver experiências de aprendizagem e conhecimento sobre os comportamentos relacionados à saúde e condições sociais que podem afetar sua saúde e dos que estão a sua volta. Assim, o trabalho realizado com estes adolescentes teve um impacto positivo em suas vidas ampliando o conhecimento para sua família e, consequentemente, o meio em que vivem, ao serem abordados temas que fazem parte de seu cotidiano deu uma resposta resolutiva para as questões atuais que os cercam. Diante disso, é possível ressaltar a relevância da iniciativa do profissional de saúde trabalhar com a promoção da saúde no espaço escolar. Enfatizamos que, com a realização dessas atividades, pode-se manter um vínculo e estabelecer parcerias com os envolvidos que fazem parte desse ambiente, no sentido de conhecer os seus problemas de saúde e buscar formas de minimizá-los, auxiliando em sua autonomia e promoção de uma melhor qualidade de vida.

\section{REFERÊNCIAS}

BRASIL. Ministério da Saúde. Secretaria de Atenção à Saúde. Departamento de Atenção Básica. Núcleo de Apoio à Saúde da Família / Ministério da Saúde, Secretaria de Atenção à Saúde, Departamento de Atenção Básica. - Brasília: Ministério da Saúde, 2014. 112 p.: il. - (Cadernos de Atenção Básica, n. 39). 
BUSS, P.M. Promoção e educação em saúde no âmbito da escola de governo em saúde da escola nacional de saúde pública. Cadernos de Saúde Pública, Rio de Janeiro, Vol. 15, 1999.

COSTA, F.S., SILVA, J.L., DINIZ, M.Z.G. A importância da interface educação/saúde no ambiente escolar como prática de promoção da saúde. Informe-se em promoção da saúde, Vol. 4, №2, Pag. 30-33, 2008.

DEMARZO, M. M. P.; AQUILANTE, A. G. Saúde Escolar e Escolas Promotoras de Saúde. In: Programa de Atualização em Medicina de Família e Comunidade. Porto Alegre, RS: Artmed: Pan-Americana, 2008. v. 3, p. 49-76.

GUBERT, F.A, SANTOS, A.C.L., ARAGÃO, K.A., PEREIRA, D.C., VIEIRA, N.F., PINHEIRO, P.N. Tecnologias Educativas no contexto escolar: estratégia de educação em saúde em escola pública de Fortaleza- CE. Revista Eletrônica de Enfermagem, 2009, Pág. 165-72.

LEFÉVRE, F. Análise de cartazes sobre esquistossomose elaborados por escolares. Revista de Saúde Pública, São Paulo, 1980.

LEONELLO, V.M., L'ABBATE,S. Educação em saúde na escola: Uma abordagem do currículo e da percepção de alunos de graduação em Pedagogia. InterfaceComunic., Saúde, Educ., Vol. 9, №18, 2006.

LIBERAL, E.F. et al. Acidentes e danos com escolares: incidência, causas e consequências. Jornal de Pediatria .v. 81, n.5(supl), p.155 - 163, 2005;

LINS, M. J. C. A. A promoção da Saúde em Alagoas: O desafio de fazer saúde tendo em perspectiva seus determinantes sociais. Secretária de Estado da Saúde de Alagoas, Superintendência de Vigilância em Saúde, Diretoria de Promoção da Saúde. Maceió: Victória Gráfica, 2010. 361 p.

LOPES, R. E.; SILVA, C. R. O campo da educação e demandas para a terapia ocupacional no Brasil. Revista de Terapia Ocupacional da Universidade de São Paulo, v.18, n. 3, p. 158-164, set./dez. 2007.

MINISTÉRIO DA EDUCAÇÃO. Disponível em:

$<$ http://portal.mec.gov.br/index.php?option=com_content\&id=14578:programa-saudenas-escolas\&ltemid=817> Acesso em: 06 de maio de 2016. 
PEREIRA, A.L.F. As tendências pedagógicas e a prática educativa nas Ciências da Saúde. Cadernos de Saúde Pública, Rio de Janeiro, v.19, n.5, p.1527-1534, 2003.

ROCHA, E. F. A Terapia Ocupacional e as ações na educação: aprofundando interfaces. Revista de Terapia Ocupacional da Universidade de São Paulo, v.18, n. 3, p. 122-127, set./dez. 2007. 